\title{
ANÁLISE DE CRESCIMENTO DO GIRASSOL EM FUNÇÃO DO SUPRIMENTO DE FÓSFORO E BORO
}

\author{
SUNFLOWER GROWTH RELATED TO THE PHOSPHORUS AND BORON SUPPLY
}

\section{Leandro Gonçalves dos SANTOS ${ }^{1}$; Ubiratan Oliveira SOUZA ${ }^{2}$; Zuleide Silva de CARVALHO ${ }^{3}$; Dário Costa PRIMO ${ }^{4}$; Anacleto Ranulfo dos SANTOS ${ }^{5}$}

1. Doutorando em Fitotecnia, Universidade Estadual do Sudoeste da Bahia - UESB, Vitória da Conquista, BA, Brasil. leandro.ifpb@gmail.com; 2. Doutorando em Fitotecnia - UESB, Vitória da Conquista, BA, Brasil; 3. Doutoranda em Ciências Agrárias, Universidade Federal do Recôncavo da Bahia - UFRB, Cruz das Almas, BA, Brasil; 4. Pós-Doutorando, Universidade Federal de Pernambuco - UFPE, Recife, PE, Brasil; 5. Professor Adjunto, Centro de Ciências Agrárias, Ambientais e Biológicas - UFRB, Cruz das Almas, BA, Brasil.

RESUMO: A cultura do girassol é de grande importância no cenário mundial por ser uma planta de múltiplas finalidades. No Brasil, o interesse do produtor por esta cultura vem crescendo a cada ano, pois além do destacado teor de óleo nos aquênios, a planta pode ser utilizada para alimentação animal na forma de silagem. Outro fator que merece destaque é que o Governo Federal em parceria com o Governo do Estado, a Petrobras S.A. e as prefeituras dos municípios envolvidos vem incentivando o plantio da oleaginosa através da agricultura familiar gerando renda aos pequenos agricultores e desenvolvimento para a região. O objetivo deste estudo foi analisar o crescimento do girassol (Helianthus annuиs L.) híbrido "Helio 358" em diferentes níveis de fósforo e boro no solo, cultivado em sistema convencional no município de Cruz das Almas, Bahia. O experimento foi conduzido no Campus da Universidade Federal do Recôncavo da Bahia, em Latossolo Amarelo coeso, no período de Julho a Novembro de 2008. O delineamento experimental utilizado foi em esquema fatorial $5 \times 2$, sendo cinco doses de fósforo $\left(0 ; 40 ; 80 ; 120\right.$ e $\left.200 \mathrm{~kg} \mathrm{ha}^{-1} \mathrm{de} \mathrm{P}\right)$ e duas de boro $\left(0\right.$ e $2 \mathrm{~kg}^{-1} \mathrm{de}^{-1}$ B), com os tratamentos distribuídos em blocos casualizados, com três repetições e amostragens na parcela a cada quinze dias. Em cada coleta avaliou-se o rendimento de matéria seca total da parte aérea, a área foliar, a altura das plantas e o diâmetro das hastes. Através da variação da matéria seca e da área foliar obteve-se a taxa de crescimento da cultura, a taxa de crescimento relativo e taxa assimilatória líquida. Verificou-se que não houve efeito significativo da interação entre fósforo e boro nas variáveis em estudo, contudo houve significância para a aplicação isolada de fósforo no crescimento do girassol. A aplicação de fósforo acelerou o desenvolvimento do girassol e o florescimento, antecipando a colheita e a obtenção do índice de área foliar ótimo.

PALAVRAS CHAVE: Helianthus annuus L. Índices fisiológicos. Adubação fosfatada.

\section{INTRODUÇÃO}

O girassol (Helianthus annuus L.) é uma cultura de importância reconhecida e que pode ser cultivado em todos os continentes. Dentre as diversas características da cultura, destaca-se seu potencial para aproveitamento econômico, produção de óleo para alimentação humana e utilização da planta, grãos e resíduos na alimentação de animais (MANDARINO, 2005; SILVA; PINHEIRO, 2005; CASTRO; FARIAS, 2005).

Atualmente, vem despertando grande interesse mundial, representando uma alternativa como matéria prima para a produção de biocombustíveis. Em 2008 a Petrobras inaugurou a primeira usina construída pela empresa, localizada na cidade de Candeias-BA, e que possui hofe uma capacidade de produção de 217,2 milhões de litros de biodiesel por ano (PORTAL BRASIL, 2011). Para a safra de 2013/14 esta unidade conta com 15,5 mil agricultores familiares contratados para produção de oleaginosas nos estados da Bahia, Sergipe, Pernambuco, Ceará, Piauí e Minas Gerais.
No Recôncavo Baiano a cultura do girassol surge como mais uma opção para a agricultura familiar gerando renda com a produção de grãos e de mel, além de incentivos governamentais que garantem a assistência técnica agrícola, sementes certificadas e preço mínimo de compra. Nesta região, predominam os Latossolos, que se caracterizam por apresentar horizonte subsuperficial coeso que limita o desenvolvimento de raízes, a aeração e o deslocamento de água no perfil. Além disso, possui baixa saturação por bases, alta saturação por alumínio e baixos valores de $\mathrm{pH}$, fatores que inibem a disponibilidade e absorção de nutrientes (REZENDE, 2000).

Todas as células vivas necessitam de fósforo (P), o que o torna um elemento muito importante é um componente de muito fósforo-açúcares necessários na fotossíntese, respiração e outros processos metabólicos, participa na formação de nucleotídeos (DNA e RNA) e de fosfolipídios presentes nas membranas (TAIZ; ZEIGER, 2006). Também é essencial no metabolismo energético, 
devido a sua presença nas moléculas de ATP, ADP, AMP e pirofosfato (SALISBURY; ROSS, 1991).

De acordo com Aguiar Neto et al. (2010), o baixo suprimento de $\mathrm{P}$ resulta na diminuição da área foliar do girassol, o que pode comprometer diretamente na capacidade fotossintética e de interceptação de luz. Malavolta et al. (1997), relatam que plantas mal nutridas em $\mathrm{P}$ apresentam acentuada redução no crescimento, atraso no florescimento e número reduzido de sementes. Epstein e Bloom (2006) relatam que algumas espécies de plantas submetidas à deficiência de $\mathrm{P}$ desenvolvem uma coloração arroxeada devido à acumulação de antocianinas nos vacúolos.

Dentre os micronutrientes, o Boro (B) é o elemento mais limitante à cultura do girassol, sendo que sua deficiência pode gerar sintomas leves ou imperceptíveis que levam a perda da produção pela queda do capítulo (ZOBIOLE et al., 2011). Para Faquin (1994), na planta o B atua como facilitador do transporte de açúcares através das membranas pelo complexo açúcar-borato. $\mathrm{O} \mathrm{B}$ auxilia na incorporação do fosfato para formar nucleotídeos, além de formar derivados que atuam como constituinte da hemicelulose da parede celular (PRADO et al., 2008; FURLANI, 2004). Pesquisadores como Bell (1997) afirmam que a maior parte dos sintomas de deficiência de B ocorrem nos tecidos mais jovens incluindo pontos de crescimento, órgãos reprodutivos, flores, frutos e grãos. Segundo Gil-Martinez (1995), o primeiro sintoma a aparecer com a deficiência de boro é a morte do ápice dos brotos e das raízes, devido ao seu requerimento na síntese de DNA. A carência de B ainda resulta na diminuição da área foliar, com desenvolvimento de folhas espessas, quebradiças e pequenas, podendo ainda ocorrer acúmulo de compostos nitrogenados nas partes mais velhas, crescimento reduzido de raízes e abortamento floral (DECHEN; NACHTIGALL 2006).

Analise quantitativa de crescimento surge como uma ferramenta importante para avaliar a produção vegetal e eficiência das diferentes formas de manejo utilizada numa cultura, sendo bastante utilizada por pesquisadores da área agrícola. É um método que descreve as condições morfofisiológicas da planta em diferentes intervalos de tempo (MAGALHÃES, 1986), não necessita de equipamentos sofisticados, e baseia-se no fato de que cerca de $90 \%$ da matéria seca acumulada pela planta, ao longo do seu crescimento, resulta da atividade fotossintética (BENINCASA, 2003). De acordo com Hunt et al. (2002), a análise de crescimento é uma ferramenta que deve ser utilizada de maneira integrativa, avaliando os componentes da planta, interpretando sua forma e utilidade.

De acordo com Peixoto e Peixoto (2009), o crescimento da planta pode ser estudado por medidas lineares (altura, diâmetro, peso), não lineares (baseadas no acúmulo de matéria seca durante certo período de tempo) e de superfície (área foliar). Severino et al. (2004), afirmam que a determinação da área foliar é importante porque as folhas são as principais responsáveis pela captação de energia solar, indispensável para a fotossíntese.

Diante dessas considerações, o presente trabalho teve como objetivo de analisar o crescimento do girassol híbrido "Helio 358" em função do suprimento de fósforo e boro.

\section{MATERIAL E MÉTODOS}

O experimento foi realizado na área experimental do Centro de Ciências Agrárias, Ambientais e Biológicas da Universidade Federal do Recôncavo da Bahia (UFRB), localizado no município de Cruz das Almas - BA, situado a 226 $\mathrm{m}$ de altitude $\left(12^{\circ} 40^{\prime} \mathrm{S} ; 3^{\circ} 06^{\prime} \mathrm{W}\right)$, em condições de campo, em Latossolo Amarelo, textura média, no período de Julho a Novembro de 2008. De acordo com a classificação de Köppen, o clima é classificado como Aw tropical quente e úmido, com temperatura média anual de $24,5^{\circ} \mathrm{C}$ e umidade relativa do ar de $80 \%$.

Baseado na análise química do solo (Tabela 1) procedeu-se a calagem e gessagem 60 dias antes do plantio. Aplicou-se $1,2 \mathrm{Mg} \mathrm{ha}^{-1}$ de calcário dolomítico e $1,2 \mathrm{Mg} \mathrm{ha}^{-1}$ de gesso agrícola, sendo essas quantidade determinadas pelo método da neutralização da acidez trocável e da elevação dos teores de $\mathrm{Ca}^{2+}+\mathrm{Mg}^{2+}$ e em função da textura do solo, respectivamente (CASTRO; OLIVEIRA, 2005).

Utilizou-se sementes de girassol híbrido "Helio 358" da Helianthus do Brasil, que têm como características o porte médio e maturação fisiológica aproximada de 90 dias após emergência (DAE), e que tem apresentado excelente desenvolvimento na região. A semeadura foi realizada no mês de Julho, em sistema de cultivo convencional aos 15 DAE procedeu-se o desbaste de maneira a garantir trinta e duas plantas a cada dez metros, com uma população final equivalente a 45000 plantas por hectare, seguindo a recomendação de Silveira et al. (2005).

No estudo do efeito das doses de P e B sobre as variáveis analisadas, utilizou-se o ensaio fatorial $5 \times 2$, sendo cinco doses de fósforo $(0 ; 40 ; 80$; 120 e $200 \mathrm{~kg} \mathrm{ha}^{-1}$ de P) e duas de boro (0 e $2 \mathrm{~kg} \mathrm{ha}^{-1}$ de $\mathrm{B}$ ), com os tratamentos distribuídos em blocos casualizados e com três repetições. Para avaliar a 
análise de crescimento da planta, foram realizadas coletas quinzenais de três plantas aleatórias a partir dos 23 DAE até o momento da colheita (maturação plena), para determinação da altura da planta $(\mathrm{cm})$, diâmetro da haste $(\mathrm{cm})$, matéria seca total da parte aérea $\left(\mathrm{g} /\right.$ planta) e área foliar $\left(\mathrm{cm}^{2}\right)$.

Tabela 1. Características químicas de amostras de solo coletado na área do experimento em três profundidades. UFRB, Cruz das Almas, BA, 2008.

\begin{tabular}{lccc}
\hline \multicolumn{1}{c}{ Características } & \multicolumn{3}{c}{ Profundidade (m) } \\
\cline { 2 - 4 } & $\mathbf{0 , 0 - \mathbf { 0 , 2 }}$ & $\mathbf{0 , 2 - \mathbf { 0 , 4 }}$ & $\mathbf{0 , 4 - 0 , 6}$ \\
\hline $\mathrm{pH} \mathrm{em} \mathrm{H} \mathrm{H}_{2} \mathrm{O}$ & 5,1 & 4,9 & 4,8 \\
$\mathrm{pH} \mathrm{em} \mathrm{CaCl}$ & 4,3 & 4,1 & 4,0 \\
$\mathrm{Al}^{3+}\left(\mathrm{cmol}_{\mathrm{c}} \mathrm{dm}^{-3}\right)$ & 0,6 & 0,5 & 0,2 \\
$\mathrm{H}^{+}+\mathrm{Al}^{3+}\left(\mathrm{cmol}_{\mathrm{c}} \mathrm{dm}^{-3}\right)$ & 2,15 & 1,98 & 2,15 \\
$\mathrm{Ca}^{2+}+\mathrm{Mg}^{2+}\left(\mathrm{cmol}_{\mathrm{c}} \mathrm{dm}^{-3}\right)$ & 2,1 & 0,8 & 0,7 \\
$\mathrm{Ca}^{2+}\left(\mathrm{cmol}_{\mathrm{c}} \mathrm{dm}^{-3}\right)$ & 0,6 & 0,6 & 0,5 \\
$\mathrm{Mg}^{2+}\left(\mathrm{cmol}_{\mathrm{c}} \mathrm{dm}^{-3}\right)$ & 1,5 & 0,2 & 0,2 \\
$\mathrm{~K}\left(\mathrm{cmol}_{\mathrm{c}} \mathrm{dm}^{-3}\right)$ & 0,131 & 0,080 & 0,057 \\
$\mathrm{P}\left(\mathrm{mg} \mathrm{dm}^{-3}\right)$ & 0,20 & 0,20 & 0,15 \\
$\mathrm{~B}\left(\mathrm{mg} \mathrm{dm}^{-3}\right)$ & 0,10 & 0,09 & 0,06 \\
$\mathrm{C} . \mathrm{O} .\left(\mathrm{g} \mathrm{dm}^{-3}\right)$ & 7,2 & 5,2 & 4,1 \\
$\mathrm{CTC}$ & 4,4 & 2,9 & 2,9 \\
$\mathrm{~V}(\%)$ & 51 & 31 & 26 \\
$\mathrm{~m}(\%)$ & 21 & 35,7 & 20 \\
\hline
\end{tabular}

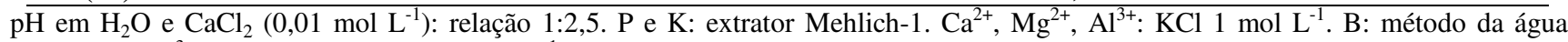
quente. $\mathrm{H}^{+}+\mathrm{Al}^{3+}$ : método $\mathrm{Ca}(\mathrm{OAc})_{2} \quad 0,5 \mathrm{~mol} \mathrm{~L}^{-1}$, pH 7. C.O.: Walkley Black.

O fósforo foi aplicado no sulco de plantio abaixo e ao lado da semente, na forma de Superfosfato triplo. O boro foi aplicado na forma de ácido bórico juntamente com a adubação de cobertura, aos 30 e 60 DAE. Além dos tratamentos estudados, aplicou-se também $80 \mathrm{~kg} \mathrm{ha}^{-1}$ de $\mathrm{K}$ e 80 $\mathrm{kg} \mathrm{ha}^{-1}$ de $\mathrm{N}$, na forma de Cloreto de potássio e Uréia, respectivamente. Essa adubação complementar foi fracionada em três partes, sendo uma no plantio e o restante juntamente com o boro, seguindo a recomendação da Embrapa para a cultura (BALLA et al., 1997).

A precipitação pluviométrica acumulada desde a semeadura até a colheita foi de $366,4 \mathrm{~mm}$, com uma média mensal de $73,3 \mathrm{~mm}$. As parcelas com área de $25,6 \mathrm{~m}^{2}$ foram constituídas de 10 linhas com 3,2 m de comprimento cada, espaçadas a $0,7 \mathrm{~m}$ entre linhas e 0,31 m entre plantas. De cada parcela foi desprezada uma linha de bordadura de cada lado e duas plantas das extremidades de cada linha.

Considerou-se como altura da planta a distância compreendida entre a superfície do solo e a extremidade apical, sendo determinada com auxilio de fita métrica. $\mathrm{O}$ diâmetro da haste foi medido a cinco centímetros acima do colo com o uso de um paquímetro. A matéria seca total resultou da soma da massa dos componentes da parte aérea (haste, pecíolo e folha) mensurada após secagem em estufa com circulação de ar forçada a $65{ }^{\circ} \mathrm{C}$ durante
72 horas até atingir massa constante. A área foliar foi determinada utilizando-se o medidor de área foliar portátil "AM300 Area Meter" da marca ADC.

A variação da matéria seca e da área foliar foi utilizada para cálculo e obtenção dos índices fisiológicos (BENINCASA, 2003): taxa de crescimento da cultura $\left(\mathrm{TCC}=\mathrm{MS} / \mathrm{t}\right.$ em g planta $^{-1} \mathrm{~d}^{-}$ $\left.{ }^{1}\right)$, taxa de crescimento relativo $(\mathrm{TCR}=\mathrm{TCC} / \mathrm{MS}$ em $\mathrm{g}^{-1} \mathrm{~d}^{-1}$ ) e taxa assimilatória líquida (TAL= TCC/AF em $\mathrm{g} \mathrm{cm}^{-2} \mathrm{~d}^{-1}$ ).

Os resultados foram submetidos às análises de variância, regressão e correlação utilizando-se o programa estatístico SAS (1996). Na análise de correlação foi inserido os dados da produção de aquênios (PROD) obtido ao final do experimento. Os índices fisiológicos TAL, TCC e TCR foram ajustados a um modelo de regressão polinomial através do programa Table Curve 2D (SYSTAT, 2002).

\section{RESULTADOS E DISCUSSÃO}

Conforme pode ser observado na Tabela 2, dentre os fatores estudados verificou-se efeito significativo $(\mathrm{p}<0,01)$ para os diferentes níveis de fósforo (P) e as épocas de coleta (D) de forma isolada em todas as variáveis analisadas ao longo do crescimento e desenvolvimento da planta. A interação entre as doses de fósforo e a época de 
coleta proporcionou efeito significativo apenas para as variáveis, altura de plantas e a matéria seca total da parte aérea. As doses de boro (B) isoladas ou em interação com as doses de fósforo e as épocas de coleta não apresentaram efeito significativo, possivelmente pela presença deste micronutriente no solo e da matéria orgânica.
O ciclo do girassol foi de 98 dias entre a emergência e a colheita, para os tratamentos que receberam fósforo, enquanto que a omissão deste nutriente retardou o florescimento em oito dias, resultando num ciclo maior, 106 dias.

Tabela 2. Resumo da análise de variância para altura (ALT), diâmetro do caule (DIA), matéria seca total (MST) e área foliar (IAF), do girassol "Helio 358”. UFRB, Cruz das Almas, BA, 2008.

\begin{tabular}{|c|c|c|c|c|c|}
\hline \multirow{2}{*}{ Fonte de Variação } & \multirow{2}{*}{ GL } & \multicolumn{4}{|c|}{ Quadrados Médios } \\
\hline & & ALT & DIA & MST & AF \\
\hline Blocos $(\mathbf{R})$ & 2 & $2139,6^{* *}$ & $0,45^{* *}$ & $6039,7^{* *}$ & $2,45 \mathrm{e}^{7 * *}$ \\
\hline Fósforo (P) & 4 & $22825,3^{* *}$ & $5,74^{* *}$ & $29444,1^{* *}$ & $5,55 \mathrm{e}^{7 * *}$ \\
\hline Boro (B) & 1 & $22,0^{\mathrm{ns}}$ & $0,05^{\mathrm{ns}}$ & $195,9^{\mathrm{ns}}$ & $1,77 \mathrm{e}^{5 \mathrm{~ns}}$ \\
\hline Idade (D) & 4 & $67445,3^{* *}$ & $5,08^{* *}$ & $85014,3^{* *}$ & $1,69 \mathrm{e}^{8 * *}$ \\
\hline P x B & 4 & $114,9^{\mathrm{ns}}$ & $0,01^{\mathrm{ns}}$ & $329,9^{\mathrm{ns}}$ & $1,39 \mathrm{e}^{6 \mathrm{~ns}}$ \\
\hline $\mathbf{D} \times \mathbf{P}$ & 16 & $763,0^{* *}$ & $0,02^{\mathrm{ns}}$ & $3755,8^{* *}$ & $4,84 e^{6 n s}$ \\
\hline $\mathbf{D} \times \mathbf{B}$ & 4 & $30,1^{\mathrm{ns}}$ & $0,01^{\mathrm{ns}}$ & $202,4^{\mathrm{ns}}$ & $4,79 \mathrm{e}^{4 \mathrm{~ns}}$ \\
\hline Resíduo & 56 & 53,7 & 0,01 & 185,1 & $6,24 \mathrm{e}^{5}$ \\
\hline CV (\%) & & 7,67 & 5,94 & 19,32 & 23,26 \\
\hline
\end{tabular}

A altura das plantas foi influenciada pelo suprimento das doses de fósforo no solo, ao longo de seu desenvolvimento, ajustando-se a um modelo polinomial (Figura 1). Aos 76 dias após emergência (DAE) a máxima altura das plantas de girassol foi de $160 \mathrm{~cm}$, obtida com a dose $120 \mathrm{~kg} \mathrm{ha}^{-1}$ de $\mathrm{P}$, caracterizando um aumento de $123,1 \%$, ou seja, $88,3 \mathrm{~cm}$ em relação às plantas que não receberam fósforo. A altura das plantas de girassol variou pouco se comparada à aplicação de $120 \mathrm{~kg} \mathrm{ha}^{-1} \mathrm{com}$ as doses 40, 80 e $200 \mathrm{~kg} \mathrm{ha}^{-1}$ de $\mathrm{P}$, indicando que entre a menor e maior dose aplicada a diferença foi de $15 \mathrm{~cm}$, mas que o suprimento de $\mathrm{P}$ é fundamental.
Assim como descrito por Castro et al. (1996) e Carvalho (2004), o crescimento inicial das plantas foi lento, sendo no florescimento o estádio de crescimento com maior altura observada. Resultados semelhantes foram encontrados por Oliveira Junior et al. (2011) em estudo com fósforo na cultura do girassol (híbrido Agrobel 960) constatou efeito significativo na altura da planta variando de 127 a $163 \mathrm{~cm}$, a medida que aumentavam os níveis de fósforo proveniente da adubação num Latossolo Vermelho-Amarelo distrófico.

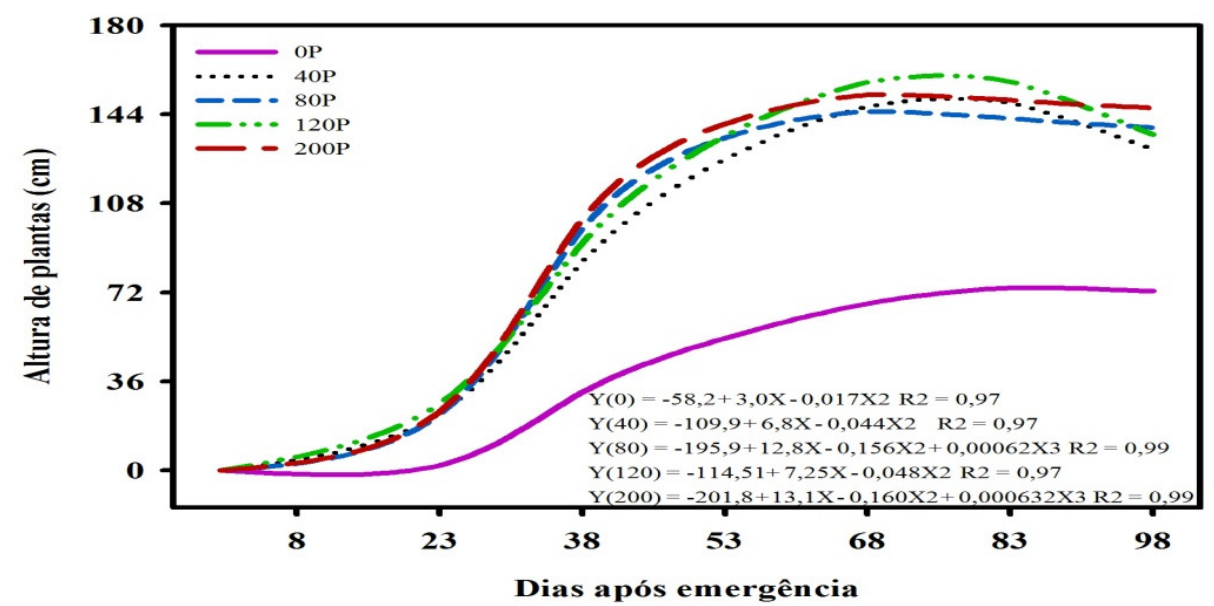

Figura 1. Influência das doses de $P$ na altura de plantas de girassol "Helio 358" ao longo de seu desenvolvimento. UFRB, Cruz das Almas, BA, 2008. 
O diâmetro do caule variou com a idade da planta e com as doses de $\mathrm{P}$, e por meio da análise de regressão se ajustou a um modelo quadrático como segue na Figura 2A e 2B. Em função da idade da planta o maior diâmetro $(1,97 \mathrm{~cm})$ foi encontrado aos 68 DAE (Figura 2A). Em relação às doses de $\mathrm{P}$ estudadas, o maior diâmetro $(1,91 \mathrm{~cm})$ foi estimado com a aplicação de $140 \mathrm{~kg} \mathrm{ha}^{-1}$ de $\mathrm{P}$, sendo este 2,1 vezes mais espesso que o encontrado em omissão de $\mathrm{P}$ (Figura 2B). Contudo, doses acima de $40 \mathrm{~kg} \mathrm{ha}^{-1}$

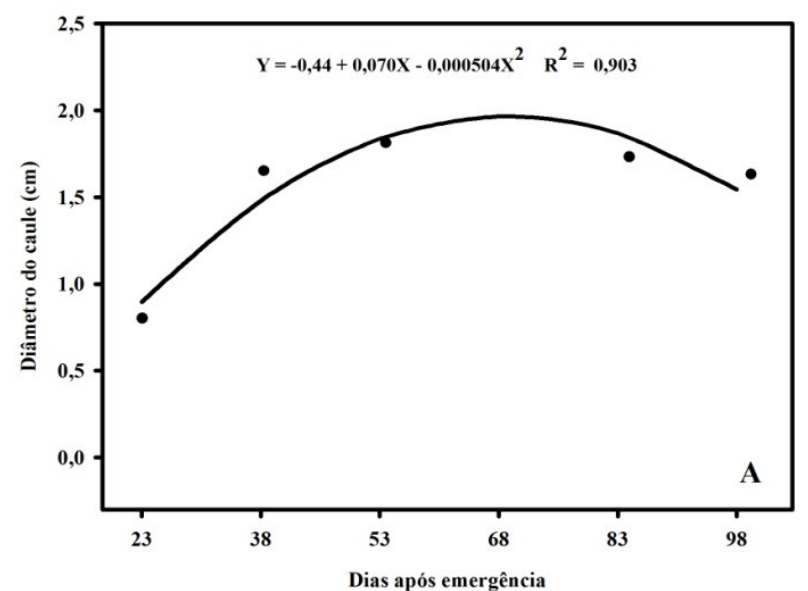

Figura 2. Influência da idade $(\mathrm{A})$ e das doses de $\mathrm{P}$ 358". UFRB, Cruz das Almas, BA, 2008.

A matéria seca total (MST) da parte aérea do girassol aumentou à medida que se elevou as doses de P aplicadas (Figura 3). Até os $38 \mathrm{DAE}$ as doses 40, 80, 120 e $200 \mathrm{~kg} \mathrm{ha}{ }^{-1}$ de $\mathrm{P}$ não influenciaram expressivamente na produção de MST, indicando que até esta fase a planta exigiu de $\mathrm{P}$ promoveram maior diâmetro do caule, fator este que proporciona maior sustentação da planta e reduz o risco de quebra ou acamamento e consequente perda na colheita. Freitas et al. (2012) relataram plantas com diâmetro caulinar variando de 1,30 a $1,52 \mathrm{~cm}$ em estudo com irrigação a partir de água de poço e de esgoto, sendo esta ultima a responsável pela obtenção do maior diâmetro devido a maior presença de nutrientes dissolvidos.

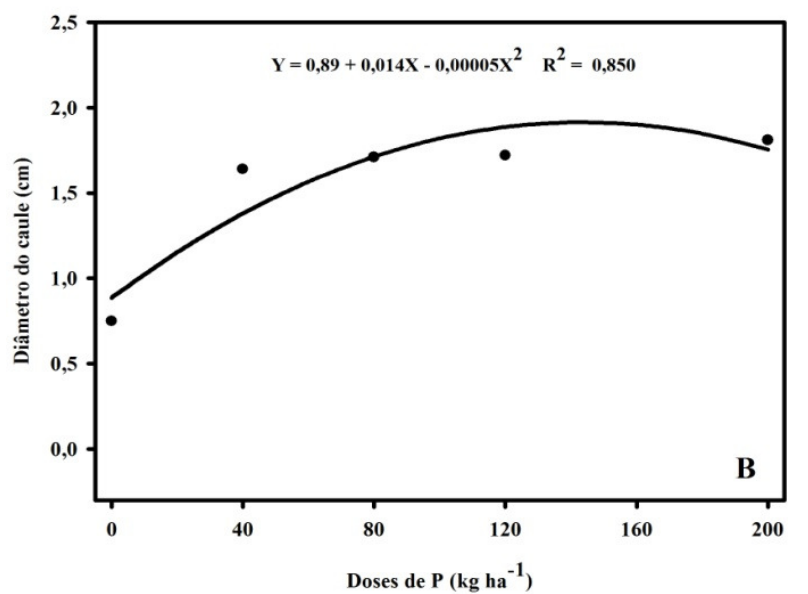

(B), no diâmetro do caule de plantas de girassol "Helio pouco $\mathrm{P}$ para produção de massa seca. Contudo, nesta fase do crescimento a omissão de $\mathrm{P}$ ocasionou uma produção $379 \%$ inferior quando comparado à aplicação de $40 \mathrm{~kg} \mathrm{ha}^{-1}$ de $\mathrm{P}$. Estes resultados indicam que este elemento é muito importante no rendimento de matéria seca do girassol.

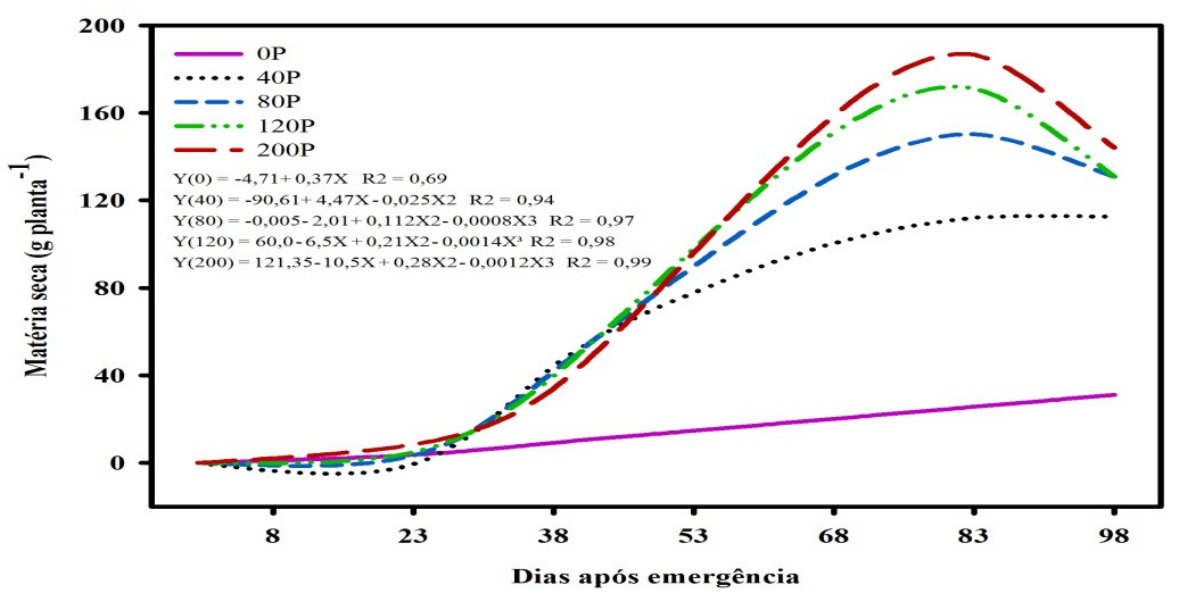

Figura 3. Influência das doses de $\mathrm{P}$ no rendimento de matéria seca total (MST) da parte aérea do girassol "Helio 358" ao longo de seu desenvolvimento. UFRB, Cruz das Almas, BA, 2008.

Através da análise de regressão, observou-se que esta variável teve sua máxima produção, 187,1 g/planta o que equivale a $8,42 \mathrm{Mg} \mathrm{ha}^{-1}$, aos $81 \mathrm{DAE}$ com a aplicação da maior dose de P. Isso resultou num incremento de 161,6 g/planta $\left(7,27 \mathrm{Mg} \mathrm{ha}^{-1}\right)$, o equivalente a $633,7 \%$ da produção de MST em relação à omissão, e de $69,8 \%, 23,4 \%$ e $9,9 \%$ em relação à aplicação de 40,80 e $120 \mathrm{~kg} \mathrm{ha}^{-1}$ de $\mathrm{P}$, 
respectivamente. Zobiole et al. (2010) avaliando a marcha de absorção de macronutrientes, observaram produção acentuada de MST atingindo o valor máximo aos 89 DAE, com 237,46 g/planta $(10,7 \mathrm{Mg}$ $\left.\mathrm{ha}^{-1}\right)$, sendo que no estudo destes autores os teores de fósforo no solo eram maiores $\left(17,0 \mathrm{mg} \mathrm{dm}^{-3}\right) \mathrm{e}$ adubou-se com $60 \mathrm{~kg} \mathrm{ha}^{-1}$ de $\mathrm{P}$.

Resultados semelhantes foram encontrados por Tomich et al. (2003), que trabalhando com diferentes cultivares obtiveram uma produção média de $171,5 \mathrm{~g} /$ planta $\left(7,72 \mathrm{Mg} \mathrm{ha}^{-1}\right)$ aos 91 DAE, com a aplicação de $49 \mathrm{~kg} \mathrm{ha}^{-1}$ de P. Em estudo com girassol híbrido M 734 em semeadura direta, Carvalho (2004), obteve o maior acúmulo de MST no período de enchimento dos aquênios, por volta dos 105 DAE com a aplicação de $78 \mathrm{~kg} \mathrm{ha}^{-1}$ de P. De acordo com Castro e Farias (2005), o máximo acúmulo de MST ocorreu aos 98 DAE com 212 $\mathrm{g} / \mathrm{planta}\left(9,54 \mathrm{Mg} \mathrm{ha}^{-1}\right)$ de MST, ou seja, também na fase de enchimento dos aquênios.

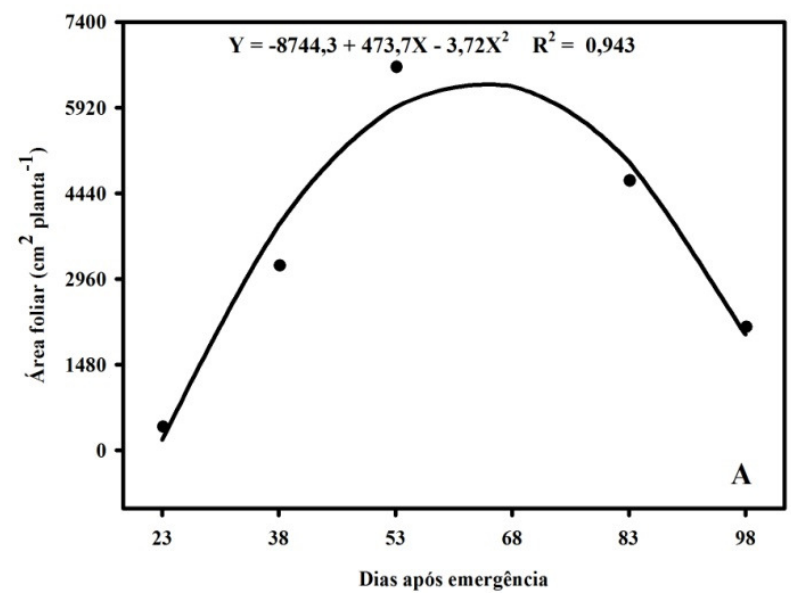

Figura 4. Influência da idade (A) e das doses de P (B) na área foliar do girassol "Helio 358". UFRB, Cruz das Almas, BA, 2008.

Em área experimental cujo solo era um Argissolo Vermelho-Amarelo com $5 \mathrm{mg} \mathrm{dm}^{-3}$ de teor de $\mathrm{P}$ e adubação com $50 \mathrm{~kg} \mathrm{ha}^{-1}$ de $\mathrm{P}$, Bezerra et al. (2014) estudando o comportamento vegetativo e produtividade do girassol Embrapa 122 em função do arranjo espacial das plantas, obtiveram aos 42 dias após semeadura $\mathrm{AF}$ de $3110,3 \mathrm{~cm}^{2}$ e 2502,8 $\mathrm{cm}^{2}$ para densidades de $30 \quad 000$ e 45000 , respectivamente. Estes valores foram inferiores possivelmente devido ao menor suprimento de $\mathrm{P}, \mathrm{o}$ que demonstra a importância deste nutriente para que a cultura expresse melhor seu potencial produtivo.

Carvalho (2004) também encontrou a máxima área foliar no florescimento pleno do girassol, efeito esse aliado a um alto teor de matéria orgânica no solo, assim como também foi observado por Mundstock e Zagonel (1994). Em estudos com
A área foliar (AF) variou com a idade da planta e com as doses de fósforo, que através da análise de regressão ajustou-se num modelo quadrático, como apresentada na Figura 4A e 4B. Em relação à idade da planta (Figura 4A), observouse um intenso aumento da AF entre 23 e 53 DAE quando se inicia o período de florescimento do girassol, sendo a maior AF $\left(6335,4 \mathrm{~cm}^{2}\right)$ observada aos 64 DAE, momento em que o florescimento era pleno. A redução gradativa da AF dos $64 \mathrm{DAE}$ até o final do ciclo é explicada pela translocação de assimilados para o enchimento dos grãos e a senescência natural das folhas. Em relação à aplicação das doses de $\mathrm{P}$, observou-se que a aplicação de $150 \mathrm{~kg} \mathrm{ha}^{-1}$ de $\mathrm{P}$ promoveu a maior área foliar, $4641 \mathrm{~cm}^{2}$ (Figura 4B). Contudo, em relação à omissão de $\mathrm{P}$, o fornecimento deste elemento na dose de $40 \mathrm{~kg} \mathrm{ha}^{-1}$ promoveu um incremento de $110,5 \%$ na área foliar.

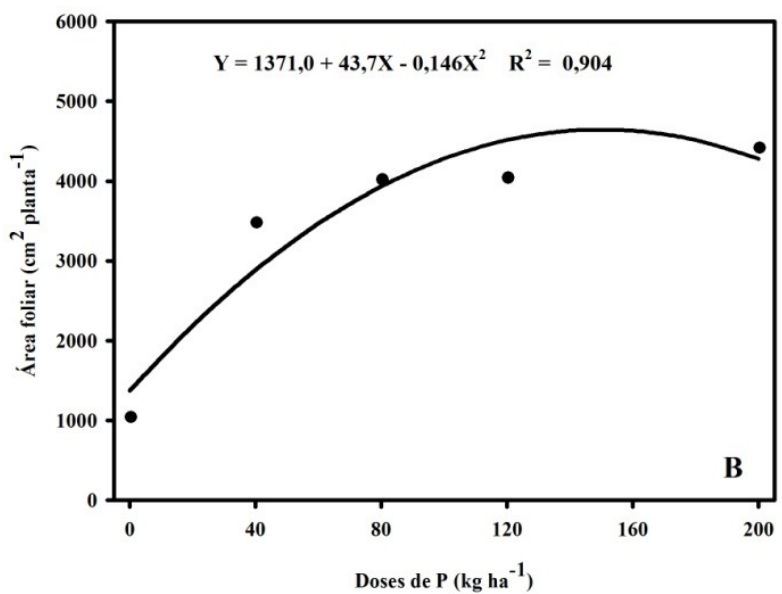

redução da área foliar no girassol através da desfolha, diversos autores como Muro et al. (2001), Erbas e Baydar (2007) e Alimohammadi e Azizov (2011), relatam reduções na produção de aquênios que pode chegar a até $92 \%$ a depender do percentual de desfolha, exemplificando bem a importância da avaliação deste parâmetro.

Os índices fisiológicos TAL, TCR e TCC, ajustaram-se ao modelo de regressão polinomial $\mathrm{Y}=$ $a+b x^{1,5}+c x^{2}+d x^{3}$. Na Figura 5, observa-se um aumento da TAL até os 29 DAE onde ocorre o ponto de máxima assimilação para todos os níveis de $\mathrm{P}$ aplicados, a partir deste ponto ocorre uma tendência natural de redução da TAL com a idade da planta, assim como relatado por Watanabe (2007), que atribui essa diminuição ao sombreamento das folhas inferiores. Aos 43 DAE a 
TAL em todos os níveis de $\mathrm{P}$ aplicado, equivalem a um valor médio de $6,7 \times 10^{-4} \mathrm{~g} \mathrm{~cm}^{-2} \mathrm{dia}^{-1}$.

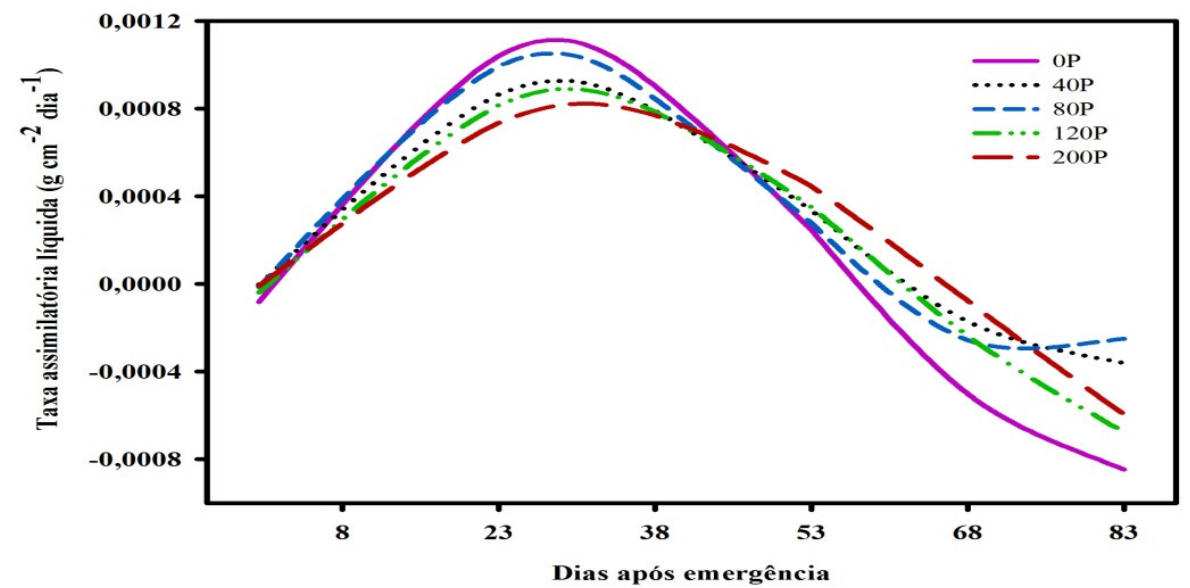

Figura 5. Influência das doses de P na taxa assimilatória líquida (TAL) do girassol "Helio 358" ao longo de seu desenvolvimento. UFRB, Cruz das Almas, BA, 2008.

Souza et al. (2013) também verificaram incrementos da TAL na fase inicial de crescimento do girassol, sendo que os valores máximos foram obtidos aos 36 DAE, em diferentes épocas de semeadura e localidade na região do Recôncavo da Bahia. Este aumento na TAL no período inicial de crescimento são interpretados por Peixoto et al. (2010) como uma resposta do aparato fotossintético a um aumento na demanda por assimilados, após um período de crescimento inicial lento.

A taxa de crescimento relativo (TCR) apresentou valor máximo aos 27 DAE na omissão e na aplicação de 40 e $80 \mathrm{~kg} \mathrm{ha}^{-1}$ de $\mathrm{P}$, e aos $29 \mathrm{DAE}$ com a aplicação de 120 e $200 \mathrm{~kg} \mathrm{ha}^{-1}$ de P (Figura 6). O decréscimo da TCR a partir dos 29 DAE está de acordo com Benincasa (2003), afirmando que esta diminuição representa o incremento da planta em massa, altura ou área foliar ao longo de determinado período, em relação ao período anterior, e que tende a diminuir com a progressão do ciclo. Comportamento semelhante foi encontrado por Peixoto (1998) avaliando cultivares de soja, e por Watanabe (2007) em estudo com girassol ornamental.

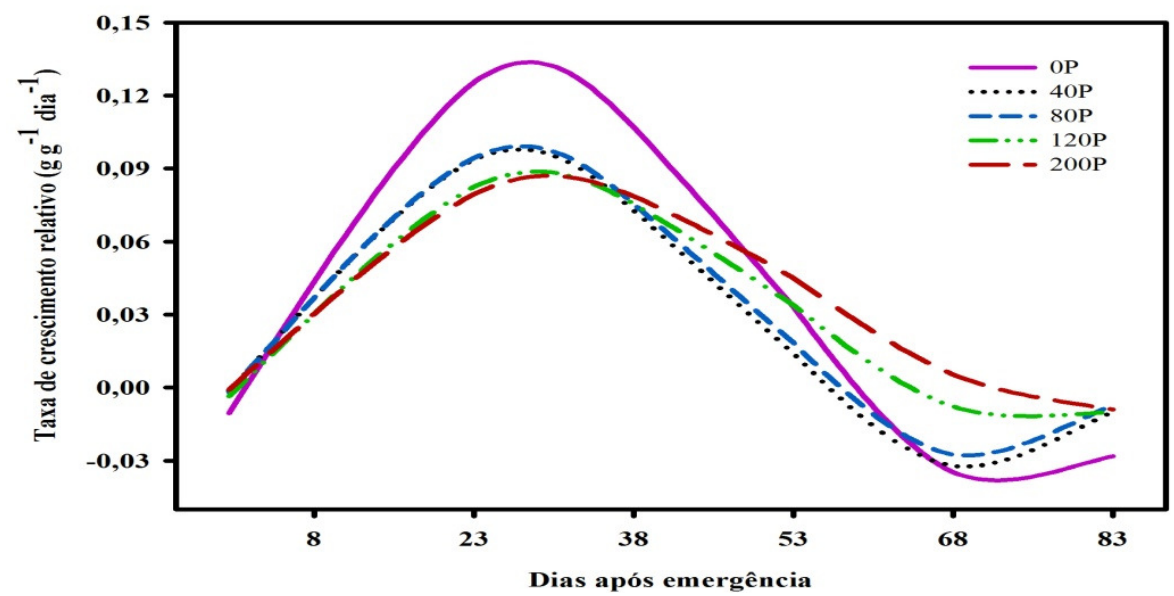

Figura 6. Influência das doses de P na taxa de crescimento relativo (TCR) do girassol "Helio 358" ao longo de seu desenvolvimento, Cruz das Almas, 2008.

A taxa de crescimento da cultura (TCC) (Tabela 3) variou com a aplicação de fósforo, sendo o maior valor observado aos 53 DAE com a aplicação de $200 \mathrm{~kg} \mathrm{ha}^{-1}$ de P. A ocorrência de valores negativos nas taxas de crescimento aos 56 DAE para TCR e TCC, é justificada por Barni (1995), uma vez que a morte de folhas excede a produção de grãos. Valores semelhantes foram encontrados por Souza et al. (2013), que observaram a TCC máxima aos 51 DAE estudando índices fisiológicos de girassol em diferentes localidade e épocas de semeadura.

Ao contrário do que parece, o índice de área foliar ótimo (IAFo) não é onde se obtém uma maior produção de fitomassa, e sim aquele que permite o máximo de fotossíntese e, consequentemente a TCC máxima. Na Tabela 3, observa-se que sem aplicação de fósforo seriam necessários 32 DAE para a planta 
adquirir um IAFo de 0,24 , contudo este valor seria insuficiente para sustentar uma produção rentável. Já com a aplicação de fósforo, o IAFo correspondente a cada dose é considerado ideal para se obter altas produtividades, como foi citado por Castro e Farias (2005), que indicam valores de IAFo entre 2,5 e 3,0 na floração plena.

Tabela 3: Valores de índice de área foliar ótimo (IAFo) encontrados pela relação entre a máxima taxa de crescimento da cultura (TCC) e o índice de área foliar do girassol "Helio 358" ao longo de seu desenvolvimento. UFRB, Cruz das Almas, BA, 2008.

\begin{tabular}{cccccc}
\hline \multirow{2}{*}{$\begin{array}{c}\text { Doses de } \mathbf{P} \\
\left(\mathbf{k g ~ h a}^{-1}\right)\end{array}$} & IAFo & \multicolumn{3}{c}{ TCC $\left(\mathbf{g ~ c m}^{-2} \mathbf{d i a}^{-\mathbf{1}}\right)$} & \multirow{2}{*}{ DAE } \\
\cline { 3 - 5 } $\mathbf{0}$ & 0,24 & $-1,9 \times 10^{-5}$ & $1,13 \times 10^{-4}$ & $-3,4 \times 10^{-4}$ & 32 \\
$\mathbf{4 0}$ & 2,75 & $-5,3 \times 10^{-5}$ & $1,28 \times 10^{-3}$ & $-7,2 \times 10^{-4}$ & 53 \\
$\mathbf{8 0}$ & 2,79 & $-7,5 \times 10^{-5}$ & $1,05 \times 10^{-3}$ & $-6,3 \times 10^{-4}$ & 50 \\
$\mathbf{1 2 0}$ & 2,56 & $-1,0 \times 10^{-4}$ & $1,20 \times 10^{-3}$ & $-1,7 \times 10^{-3}$ & 46 \\
$\mathbf{2 0 0}$ & 3,09 & $-6,6 \times 10^{-5}$ & $1,70 \times 10^{-3}$ & $-1,9 \times 10^{-3}$ & 53 \\
\hline
\end{tabular}

Observou-se que aplicando 40 ou $200 \mathrm{~kg}$ ha1 de $\mathrm{P}$ o IAFo seria alcançado aos 53 DAE correspondendo a 2,75 e 3,09, respectivamente. Contudo, se o interesse for obter um IAFo suficiente para promover altas produtividades, em um menor espaço de tempo, o ideal seria doses entre 80 e 120 $\mathrm{kg} \mathrm{ha}^{-1}$ de P. Os valores de IAFo obtidos neste estudo foram semelhantes aos observados por Souza et al. (2013), que variaram entre 1,97 e 3,40 aos 51
DAE com semeadura do girassol Embrapa $122 \mathrm{em}$ diferentes épocas de semeadura e localidades, com população de 45000 plantas ha $^{-1}$.

Verificou-se que existe correlação positiva altamente significante (Tabela 4) entre as variáveis MST aos 83 DAE e a produção de aquênios. Com base nessa correlação positiva, é possível estimar com antecedência a produção de aquênios pela produção de matéria seca.

Tabela 4: Coeficiente de correlação linear entre os valores médios de índice de área foliar (IAF) e matéria seca total (MST) aos 53 e 83 dias após emergência, e da produção de aquênios (PROD) do girassol "Helio 358 ". UFRB, Cruz das Almas, BA, 2008.

\begin{tabular}{ccccc}
\hline Variável & IAF 83 & MST 53 & MST 83 & PROD \\
\hline IAF 53 & $0,79^{* *}$ & $0,97^{* *}$ & $0,76^{* * *}$ & $0,86^{* *}$ \\
IAF 83 & & $0,83^{* *}$ & $0,97^{* *}$ & $0,94^{* *}$ \\
MST 53 & & $0,82^{* *}$ & $0,88^{* *}$ \\
MST 83 & & & $0,93^{* *}$ \\
\hline
\end{tabular}

** significativo a $1 \%$.

Na Figura 7 é possível contrastar o efeito do fósforo no desenvolvimento e florescimento do girassol. Devido à omissão deste elemento o florescimento foi retardado em oito dias, o que resultou num ciclo maior, quando comparado às plantas onde foram supridas com o P. 


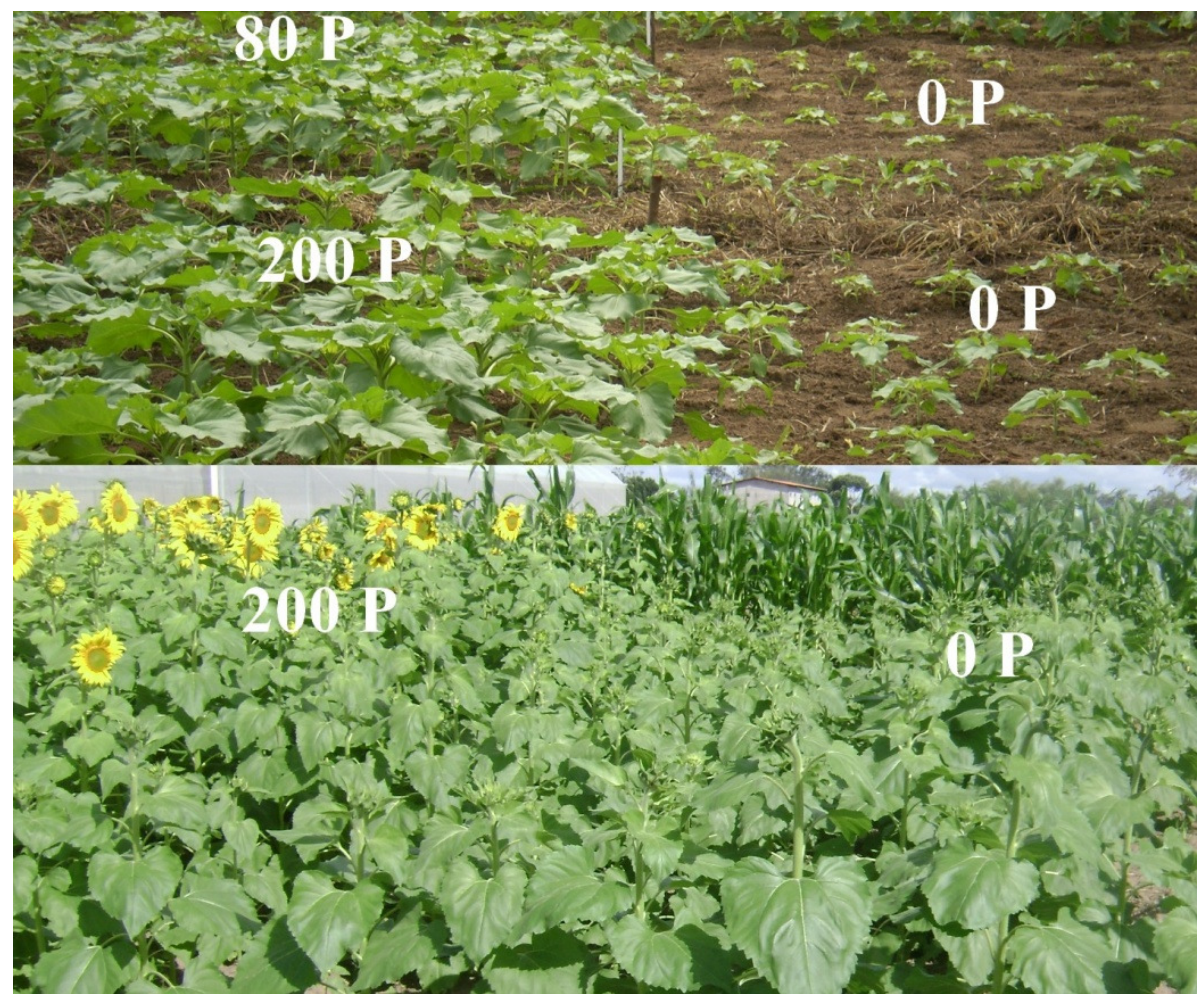

Figura 7. Desenvolvimento e florescimento do girassol "Helio 358" retardado pela omissão do fósforo. UFRB, Cruz das Almas, BA, 2008.

\section{CONCLUSÕES}

Não houve efeito significativo entre a interação do Boro e do Fósforo nas variáveis estudadas.

A omissão de fósforo limitou drasticamente o desenvolvimento do girassol, retardou o florescimento e reduziu a produção de aquênios.
A exigência do fósforo para crescimento em altura e diâmetro, produção de matéria seca e área foliar é maior a partir dos 38 dias após emergência.

O IAFo suficiente para promover altas produtividades foi obtido em menor espaço de tempo com a aplicação de $120 \mathrm{~kg} \mathrm{ha}^{-1}$ de $\mathrm{P}$.

\begin{abstract}
The sunflower crop is of great importance on the world stage to be a multi-purpose plant. In Brazil, the interest of the producer of this crop is growing every year, because besides the highlighted achene oil content, the plant can be used for animal feed in the form of silage. Another factor worth mentioning is that the Federal Government in partnership with the State Government, Petrobras S.A. and municipal governments involved has encouraged the planting of oilseed by family farms generating income for small farmers and development for the region. The purpose of this study was to analyze the growth of sunflower (Helianthus annuиs L.) hybrids "Helio 358" at different levels of phosphorus and boron in the soil, grown in conventional system in Cruz das Almas, Bahia. The experiment was conducted on the campus of the Universidade Federal do Recôncavo da Bahia, in Oxisoil, from July to November 2008. The experimental design was a $5 \times 2$ factorial design, with five levels of phosphorus $\left(0,40,80,120\right.$ and $\left.200 \mathrm{~kg} \mathrm{ha}^{-1} \mathrm{P}\right)$ and two boron $\left(0\right.$ and $\left.2 \mathrm{~kg} \mathrm{ha}^{-1} \mathrm{~B}\right)$, with treatments arranged in a randomized complete block design with three replications and plot sampling in a fortnight. At each sampling evaluated the yield of total dry matter of shoots, leaf area, plant height and diameter of the rods. By varying the dry matter and leaf area obtained the rate of crop growth, the relative growth rate and assimilation rate. It was found that there was no significant interaction between phosphorus and boron in the variables under study, but there was significance to the isolated phosphorus application on the growth of sunflower. Phosphorus application accelerated the development and flowering sunflower, anticipating harvesting and obtaining optimal leaf area index.
\end{abstract}

KEYWORDS: Helianthus annииs L. Physiologic indexes. Phosphorus fertilization. 


\section{REFERÊNCIAS}

AGUIAR NETO, P.; OLIVEIRA, F. A.; MARQUES, L. F.; RODRIGUES, A. F.; SANTOS, F. G. B. Efeitos da aplicação do fósforo no crescimento da cultura do girassol. Revista Verde, Mossoró, v. 5, n. 4, p. 148-155, 2010.

ALIMOHAMMADI, R.; AZIZOV, I. Defoliation effects on yield and yield components of sunflower cultivars (Helianthus annuus L.). Int. J. of AgriScience, Kassel, v. 1, n. 7, p. 361-365, 2011.

BALLA, A.; CASTIGLIONI, V. B. R.; CASTRO, C. Colheita do Girassol. Londrina: EMBRAPA CNPSo, 1997. (EMBRAPA-CNPSo. Doc, n. 92).

BARNI, N. A.; BERLATO, M. A.; SANTOS A. O.; SARTORI G. Análise de crescimento do girassol em resposta a cultivares, níveis de adubação e épocas de semeadura. Pesq. Agrop. Gaúcha, Porto Alegre, v. 1, n. 2, p. 167-184, 1995.

BELL, R. W. Diagnosis and prediction of boron deficiency for plant production. In: DELL, B.; BROWN, P. H.; BELL, R. W. (eds). Boron in soils and plants: reviews. Dordrecht: Kluwer Academic Publishers, 1997. p. 149-168. http://dx.doi.org/10.1007/978-94-011-5580-9_10 http://dx.doi.org/10.1007/978-94-011-5564-9

BENINCASA, M. M. P. Análise de crescimento de plantas (noções básicas). 2.ed. Jaboticabal: FUNEP, 2003, 41p.

BEZERRA, F. T. C.; DUTRA, A. S.; BEZERRA, M. A. F.; FILHO, A. F. O.; BARROS, G. L. Comportamento vegetativo e produtividade de girassol em função do arranjo espacial das plantas. Rev. Ciênc. Agron.,

Fortaleza, v. 45, n. 2, p. 335-343, 2014.

CARVAlHO, D. B. Análise de crescimento de girassol em sistema de semeadura direta. Rev. Acad., Ciênc. Agrár. Ambient., Curitiba, v. 2, n. 4, p. 63-70, 2004.

CASTRO, C.; CASTIGLIONI, V. B. R.; BALLA, A.; LEITE, R. M. V. B. C.; KARAM, D.; MELLO, H. C.; GUEDES, L. C. A.; FARIAS, J. R. B. A Cultura do girassol. Londrina: EMBRAPA-CNPSo, 1996. p. 38. (Circular Técnica, 13).

CASTRO, C.; FARIAS, J. R. B. Ecofisiologia do girassol. In: LEITE, R. M. V. B. de C.; BRIGHENTI, A. M.; CASTRO, C. (eds). Girassol no Brasil. Londrina: Embrapa Soja, 2005, p.161-218.

CASTRO, C.; OLIVEIRA, F. A. Nutrição e adubação do girassol. In: LEITE, R. M. V. B. de C.; BRIGHENTI, A. M.; CASTRO, C. (eds). Girassol no Brasil. Londrina: Embrapa Soja, 2005, p. 317-374.

DECHEN, A. R.; NACHTIGALL, G. R. Micronutrientes. In: FERNANDES, M. F. (ed). Nutrição Mineral de Plantas. Viçosa: Sociedade Brasileira de Ciência do Solo, 2006, p. 327-354.

EPSTEIN, E.; BLOOM, A. J. Nutrição Mineral de Plantas: Princípios e Perspectivas. 2. ed. Trad. NUNES, M. E. T. Londrina: Editora Planta, 2006. 403p.

ERBAS, S.; BAYDAR, H. Defoliation effects on sunflower (Helianthus annuus L.) seed yield and oil quality. Turk J. Biol., Ankara, v. 31, p. 115-118, 2007.

FAQUIN, V. Nutrição mineral de plantas. Lavras: ESAL/FAEPE, 1994, 227p.

FREITAS, C. A. S.; SILVA, A. R. A.; BEZERRA, F. M. L.; ANDRADE, R. R.; MOTA, F. S. B; AQUINO, B. F. Crescimento da cultura do girassol irrigado com diferentes tipos de água e adubação nitrogenada. R. Bras.

Eng. Agríc. Ambiental, Campina Grande, v. 16, n. 10, p. 1031-1039, 2012. 
FURLANI, A. M. C. Nutrição mineral. In: KERBAUY, G. B. (ed). Fisiologia vegetal. Rio de Janeiro: Guanabara Koogan, 2004, p. 40-75.

GIL-MARTINEZ, F. Elementos de fisiología vegetal: relationes hídricas, nutrición mineral, transporte, metabolismo. Madrid: Ediciones Mundi-Prensa, 1995, p. 249-283.

HUNT, R.; CAUSTON, D. R.; SHIPLEY, B.; ASKEW, A. P. A modern tool for classical growth analysis. Ann. Bot., United Kingdom, v. 90, p. 485-488, 2002.

MAGALHÃES, A. C. N. Análise quantitativa de crescimento. In: FERRI, M.G. Fisiologia vegetal 1. 2. ed. São Paulo: EPU, 1986, p. 331-350.

MALAVOLTA, E.; VITTI, G. C.; OLIVEIRA, S. A. Avaliação do estado nutricional das plantas. 2. ed. Piracicaba: Associação Brasileira para Pesquisa da Potassa e do Fosfato, 1997, 319p.

MANDARINO, J. M. G. Óleo de girassol como alimento funcional. In: LEITE, R. M. V. B. de C.;

BRIGHENTI, A. M.; CASTRO, C. (eds). Girassol no Brasil. Londrina: Embrapa Soja, 2005, p. 43-49.

MUNDSTOCK, C. M.; ZAGONEL, J. Perfil de área foliar de duas cultivares de girassol sob doses e épocas de aplicação de nitrogênio em cobertura. Pesq. agropec. bras., Brasília, v. 29, n. 6, p. 847-851. 1994.

MURO, J.; IRIGOYEN, I.; MILITINO, A. F.; LAMSFUS, C. Defoliation effects on sunflower yield reduction. Agron. J., Madison, v. 93, may-june, p. 634-637, 2001.

OLIVEIRA JUNIOR, A.; CASTRO, C.; OLIVEIRA, F. A.; LEITE, R. M. V. B. C.; RODAK, B. W. Fósforo na cultura do girassol. In: REUNIÃO NACIONAL DE PESQUISA DE GIRASSOL, 19., 2011. Anais... Aracaju, 2011. p.67-70.

PEIXOTO, C. P. Análise de crescimento e rendimento de três cultivares de soja (Glicyne max (L) Merrill) em três épocas de semeadura e três densidades de plantas. Piracicaba, 1998. 151p. Tese (Doutorado em Fitotecnia) - Escola Superior de Agricultura “Luiz de Queiroz” Universidade de São Paulo.

PEIXOTO, C. P.; LIMA, J. F.; SILVA, V.; BORGES, V. P.; MACHADO, G. S. Índices fisiológicos de cultivares de mamoneira nas condições agroecológicas do Recôncavo Baiano. Magistra, Cruz das Almas, v. 22, n. 3,4, p. 168-177, 2010.

PEIXOTO, C. P.; PEIXOTO, M. F. S. P. Dinâmica do crescimento vegetal. In: CARVALHO, C. A. L et al. Tópicos em Ciências Agrárias. Universidade Federal do Recôncavo da Bahia, 2009. p. 39-53.

PORTAL BRASIL. Primeira usina de biodiesel completa três anos. Disponível em < http://www.brasil.gov.br/infraestrutura/2011/07/primeira-usina-de-biodiesel-completa-tres-anos $>$. Acesso em: 27 fev. 2014.

PRADO, R. M.; ROZANE, D. E.; VALE, D. W.; CORREIA, M. A. R; SOUZA, H. A. Nutrição de Plantas: diagnose foliar em grandes culturas. 1. ed. Jaboticabal: FUNEP, 2008. 301p.

REZENDE, J. O. Solos coesos dos Tabuleiros costeiros: limitações agrícolas e manejo. Salvador: SEAGRISPA, 2000, 117p.

SALISBURY, F. B.; ROSS, C. W. Plant physiology. 4. ed. California: Wadsworth Publishing Company, 1991, $682 p$.

SAS, Institute. SAS/STAT. User's guide, version 6.11. 4. ed. Cary, Statistical Analysis System Institute, 1996. v. 2,842 p. 
SEVERINO, L. S.; CARDOSO, G. D.; VALE, L. S.; SANTOS, J. W. Método para determinação da área foliar da mamoneira. Rev. Oleag. Fibr., Campina Grande, v. 8, n. 1, p. 753-762, 2004.

SILVA, C. A.; PINHEIRO, J. W. Girassol na alimentação de suínos e aves. In: LEITE, R. M. V. B. de C.; BRIGHENTI, A. M.; CASTRO, C. (eds). Girassol no Brasil. Londrina: Embrapa Soja, 2005, p. 93-121.

SILVEIRA, J. M.; CASTRO, C.; MESQUITA, C. M; PORTUGAL, F. A. F. Semeadura e manejo da cultura do girassol. In: LEITE, R. M. V. B. de C.; BRIGHENTI, A. M.; CASTRO, C. (eds). Girassol no Brasil. Londrina: Embrapa Soja, 2005, p. 375-409.

SOUZA, L. H. B.; PEIXOTO, C. P.; LEDO, C. A. S.; SILVEIRA, P. S.; OLIVEIRA, D.; SANTOS, J. M. S. Índices fisiológicosde girassol em diferentes épocas de semeadura e densidade de plantas no Recôncavo da Bahia. Magistra, Cruz das Almas, v. 25, n. 2, p. 94-108, 2013.

SYSTAT, Inc. Table Curve 2D version 5.01 - automated curve fitting and equation discovery. 2002.

TAIZ, L.; ZEIGER, E. Plant physiology. 4. ed. Sunderland: Sinauer Associates, 2006, 719p.

TOMICH, T. R.; RODRIGUES, J. A. S.; GONÇALVES, L. C.; TOMICH, R. G. P.; CARVALHO, A. U. Potencial forrageiro de cultivares de girassol produzidos na safrinha para silagem. Arq. Bras. Med. Vet. e Zootec., Belo Horizonte, v. 55, n. 6, p. 756-762, 2003.

WATANABE, A. A. Desenvolvimento de plantas de girassol (Helianthus annuus L. cv. Pacino) com variação de nutrientes na solução nutritiva e aplicação de daminozide. Botucatu, 2007, 105f. Dissertação (Mestrado em Ciências Biológicas) - Instituto de Biociências, Universidade Estadual de São Paulo.

ZOBIOLE, L. H. S.; CASTRO, C.; OLIVEIRA, F. A.; OLIVEIRA JUNIOR, A. Marcha de absorção de macronutrientes na cultura do girassol. R. Bras. Ci. Solo, Viçosa, 34:425-433, 2010.

ZOBIOLE, L. H. S.; CASTRO, C.; OLIVEIRA, F. A.; OLIVEIRA JUNIOR, A.; MOREIRA, A. Sunflower micronutrient uptake curves. Ciênc. agrotec., Lavras, v. 35, n. 2, p. 346-353, 2011. 